\title{
Etnicidad, política y medios de comunicación. Los rankülches de la provincia de San Luis, Argentina
}

Ethnicity, politics and media. The rankülches of the province of San Luis, Argentina

Etnicidade, política e mídia. Os rankülches da província de San Luis, Argentina

María Vanesa GIACOMASSO

INCUAPA-CONICET - UNICEN, Argentina / vanegiacoo5@gmail.com

Chasqui. Revista Latinoamericana de Comunicación

$N .^{o} 135$, agosto-noviembre 2017 (Sección Informe, pp. 361-379)

ISSN 1390-1079 / e-ISSN 1390-924X

Ecuador: CIESPAL

Recibido: 22-11-2016 / Aprobado: 11-04-2017 


\title{
Resumen
}

El presente trabajo busca analizar las formas de visibilización del pueblo indígena rankülche de San Luis (Argentina) en la prensa gráfica, en un contexto caracterizado por la puesta en práctica de acciones reivindicatorias del gobierno provincial durante el siglo XXI. Se trata de la restitución de tierras en el 2007 y la construcción de "Pueblo Ranquel" para la vida en comunidad de esta población, inaugurado en 2009. El objetivo es examinar las notas periodísticas, poniendo especial atención a las representaciones construidas hacia los indígenas, así como en torno a la relación emergente entre estos y el Estado. La indagación se centra en las noticias de El Diario de la República, cabecera provincial, aunque también incluye publicaciones de otros diarios nacionales.

Palabras clave: visibilización indígena; prensa gráfica; discursos; pueblo rankülche.

\begin{abstract}
This paper aims to analyze the visibilization of the indigenous people rankülche of San Luis (Argentina) in the press, in a context characterized by the implementation of actions by the provincial government during the 21st century. This is the restitution of land in 2007 and the construction of "Pueblo Ranquel" for the community life of this population, inaugurated in 2009. The objective is to examine the journalistic notes, paying special attention to the representations built towards the natives, as well as around the emerging relation between them and the state. The focus is set on news of El Diario de la República, at the province capital, although also includes publications of other national newspapers.
\end{abstract}

Keywords: indigenous visibilization; press; discourses; rankülche people.

\section{Resumo}

O presente trabalho busca analisar as formas de visibilização dos povos indígenas rankülche de San Luis (Argentina) na mídia impressa, em um contexto caracterizado pela implementação de ações reivindicadas ao governo provincial durante o século XXI. Trata-se da restituição de terras em 2007 e a construção de "Pueblo Ranquel", inaugurado em 2009, para fomentar a vida em comunidade desta população,. Nosso objetivo é examinar as notícias, com atenção especial às representações construídas sobre os indígenas, assim como em torno à relação emergente entre estes e o estado. A análise se centra nas notícias de El Diario de la República, chapéu 'província', mas também inclui publicações de outros jornais nacionais.

Palavras-chave: visibilização indígena; mídia impressa; discursos; povo rankülche. 


\section{Introducción}

En la primera década del siglo XXI se implementaron en la provincia de San Luis una serie de medidas vinculadas a la reivindicación indígena que incluyó a la comunidad rankülche ${ }^{1}$, considerada originaria de la región. En el año 2007, el gobierno provincial, encabezado por el gobernador Alberto Rodríguez Saá ${ }^{\text {, }}$ sancionó la Ley No V-0600-07 que reconoce "la preexistencia étnica y cultural de todas las comunidades originarias del territorio" y establece "la restitución de las tierras que históricamente les han pertenecido" (art. 2), en concordancia con el mandato constitucional establecido en el art. 75 inc. 17 de la Constitución Nacional. En ese mismo año se concreta la restitución de tierras a pobladores de la provincia autorreconocidos rankülches y comienzan a desarrollarse las obras para la conformación de "Pueblo Ranquel", que se inauguró dos años más tarde, en mayo de 2009. Este pueblo cuenta desde su fundación con 24 viviendas, distribuidas en dos barrios de 12 casas cada uno, un hospital y una escuela para la educación de los niños y jóvenes en edad escolar. Posee el carácter transitorio de "Municipio Ranquel" que recibe la coparticipación del Estado Provincial. A través de un trabajo de campo etnográfico realizado con la comunidad (Giacomasso, 2016) pudo relevarse que los habitantes del pueblo son actualmente alrededor de 110 y realizan actividades vinculadas con el campo y la hacienda, con la enseñanza escolar y con el mantenimiento y limpieza de la escuela y el hospital.

Estos actos de "reparación cultural" hacia los rankülches, así como también las tareas que desarrollan, son conocidos por los ciudadanos de la región principalmente a través de los medios de comunicación que los difunden. Dicho argumento se plantea desde una concepción que entiende que la mayoría de los conocimientos que las personas poseen acerca de las cuestiones públicas no provienen de la experiencia personal directa sino de los medios que actúan como principal fuente de información (McCombs, 2004).

A raíz de ello, este artículo tiene como propósito central identificar los modos en que se visibilizan los indígenas rankülches y los acontecimientos de reivindicación relacionados a través del relevamiento de las representaciones que, principalmente, El Diario de la República, construye y divulga sobre esta temática. Este trabajo se enmarca en algunos aportes del Análisis Crítico del Discurso que refieren al papel del lenguaje en la estructuración de relaciones de poder en la sociedad (Fowler, 1979; Wodak, 1989). Desde esta perspectiva se

1 El pueblo rankülche o ranquel es considerado uno de los pueblos preexistentes al Estado Nacional, cuyo territorio originariamente comprendía desde el poniente del Río Salado-Río Cuarto, hasta el Río Negro, abarcando parte de Santa Fe, Córdoba, San Luis, Mendoza hasta el Neuquén, La Pampa y la actual provincia de Buenos Aires (Canuhé, 2010). Su denominación se corresponde con las especificidades del hábitat-geográfico: rankül-caña o carrizo y che- hombre o gente significa "gente de las cañas o de los carrizales".

2 Fue elegido gobernador de la provincia por el Partido Justicialista en el año 2003 y reelecto en el 2007. Actualmente cumple su tercer mandato, desde el año 2015. Su hermano, Adolfo, ejerció como gobernador de San Luis cinco veces consecutivas (entre 1983 y 2001), lo que da cuenta de la permanencia, el liderazgo y la centralidad que dicha familia ha adquirido en las gestiones de gobierno provinciales. 
entiende que los discursos, situados en una coyuntura socio-histórica determinada, estructuran áreas de conocimiento, expresan y despliegan identidades y relaciones, al tiempo que las constituyen y las configuran (Fairclough \& Wodak, 1997). Ello se relaciona, a su vez, con la consideración de los medios como constructores activos de la realidad: "no son solamente dispositivos de reproducción de un 'real' al que copian más o menos correctamente, sino más bien dispositivos de producción de sentido" (Verón, 2001, p. 14).

\subsection{El contexto histórico, político y social de los pueblos indígenas en Argentina}

Es sabido que la experiencia histórica argentina en torno a los pueblos indígenas está estrechamente vinculada con las políticas llevadas a cabo por el Estado. Desde allí se entiende que la relación aboriginalidad y Estado-Nación está atravesada por una construcción mutua en cada época y contexto determinado (Briones, 1998).

Históricamente, el proyecto de Nación Argentina implicó una ruptura con el pasado indígena y negó cualquier influencia que no fuera la hispano-católica, desplazando las historias de los diversos pueblos y comunidades culturalmente diferenciados. En general, se impulsó un modelo en el que se valoraron hechos y personajes históricos que fueron reconocidos y legitimados como parte del patrimonio cultural nacional, en desmedro de los pueblos indígenas que fueron excluidos e invisibilizados y/o considerados en el relato oficial como inferiores, bárbaros, sin civilización y en algunos casos como invasores (Navarro Floria, 1999; Tamagno, 2002). Para las elites intelectuales de la época, la presencia de la población indígena significaba un impedimento para el "progreso" y la "civilización" del país (Balazote \& Radovich, 1992; Bonfil Batalla, 2004; Slavsky, 1992). De acuerdo con esta ideología el "problema indígena" debía resolverse ya sea por invisibilización o por extinción (Carrasco, 2002) para lo cual, hacia el último cuarto del siglo XIX, primó una política de exterminio que halló su máxima expresión en la denominada "Conquista del Desierto" (de 1879 a 1885), basada en sucesivas campañas militares comandadas por el general Julio A. Roca que lograron desarticular y desgastar a los grupos más organizados (Carrasco \& Briones, 1996).

Sin embargo, la histórica relación del Estado con los pueblos indígenas -signada por la violencia física, la exclusión permanente y la discriminación abiertacomenzó a reconfigurarse en el siglo XX a partir de la reconquista de la democracia en 1983, la entrada en vigor de la reforma constitucional y el discurso de los derechos humanos emergente (tanto a nivel nacional como internacional), los cuales sentaron las bases políticas para la reemergencia indígena y su visibilización. Este proceso se vio favorecido, particularmente, a partir de lo que se denominó una “juridización de lo indígena” (Gómez, 1997; ver también Frites, 2011), que llevó a intensificar procesos de autoidentificación étnica donde se reivindican aspectos sociales y culturales vinculados con la preexistencia étnica de los pueblos en el territorio. Al respecto, entrelas primeras medidas legales se destaca la Ley Nacional de 1985 sobre Política Indígena y Apoyo a las Comunidades Aborígenes que creó el Instituto Nacional de Asuntos Indígenas (INAI) y la reforma de la Constitución 
Nacional de 1994 que incluyó el artículo 75 inc. 17 que reconoce "la preexistencia étnica y cultural de los pueblos indígenas al Estado Argentino" y garantiza "el respeto a su identidad (...) y a la posesión y propiedad comunitaria de las tierras que tradicionalmente ocupan". Además, más recientemente, en Argentina se sancionó la Ley de Restitución de Restos Indígenas del año 2001 (Decreto reglamentario 701/10) y la Ley Nacional de Emergencia a la Propiedad Comunitaria del año 2006. Por otra parte, en materia de derecho internacional, este proceso se evidencia en la suscripción del país al Convenio 169 de la Organización Internacional del Trabajo (OIT), ratificado en el 2000 y a la Declaración de las Naciones Unidas sobre los Derechos de los Pueblos Indígenas (ONU, 2007).

En este marco los grupos indígenas adquieren visibilidad jurídica y social y toman impulso como movimiento a favor de un conjunto de reclamos y problemas comunes y específicos que se centran principalmente en el derecho al territorio y con este al "entramado simbólico de la identidad y la reproducción del grupo y su cultura” (Lazzari, 2007, p. 14).

Esta contextualización -aunque breve- resulta fundamental para comprender que las acciones implementadas a favor de los pueblos indígenas de San Luis y su visibilización pública no pueden comprenderse como un hecho aislado, sino como parte de complejos procesos que han transformado a las sociedades de América Latina en escenario de reemergencias indígenas. Sin duda lo que se destaca de esta provincia argentina es, además de la devolución de tierras, la construcción de viviendas para que pobladores autorreconocidos como rankülches vivan comunitariamente en el nuevo pueblo. Estos hechos tuvieron una destacada difusión en El Diario de la República, cuestión que llevó interés a recuperar sus noticias para analizar los contenidos, así como las valoraciones y representaciones que predominan acerca de lo indígena y los actos de reivindicación.

Cabe aclarar que el concepto de representación aquí utilizado se entiende como construcción socio-cognitiva que podría definirse como un conjunto de informaciones, creencias, opiniones y actitudes a propósito de un objeto determinado. En este sentido, las representaciones no serían un simple reflejo de la realidad, sino una organización significante de la misma, integrada por un sistema de valores y conocimientos de determinados grupos, dependiendo de la historia y del contexto ideológico que lo envuelve. En términos generales, puede decirse que es gracias a las representaciones que las personas hacen inteligible la realidad física y social (Abric, 1994; Jodelet, 1993; Marcová, 1996; Moscovici, 1993). A su vez, resulta clave la noción más específica de representaciones mediáticas, en tanto construcciones realizadas por los medios de comunicación, los cuales funcionan como portadores responsables -junto con otros sistemas simbólicos- de trazar los tópicos, las gramáticas, los lenguajes a través de los cuales una sociedad se ordena y se piensa a sí misma (Caletti, 2006; Cebreli \& Rodríguez, 2013). En este marco, los medios deben entenderse como "operadores de visibilidad y traducibilidad", aunque al mismo tiempo como agentes de invisibilidad, capaces de hacer imperceptibles ciertos temas, actores sociales y perspectivas (Cebreli \& Rodríguez, 2013). 


\subsection{Sobre el corpus seleccionado}

Para el análisis del tema planteado se utilizó un corpus de publicaciones efectuadas por El Diario de la República de San Luis. La elección de este medio se basó en que se trata del diario más antiguo, con sede en la capital provincial y único en versión impresa que se sostiene desde 1966, lo que da cuenta de su legitimidad y reconocimiento. Además es cabecera de la provincia, con llegada a todas las ciudades provinciales, lo cual se convierte en una característica crucial para comprender cómo este diario monopólico produce agenda en los demás medios (McCombs, 2004) y contribuye así a que sus discursos se reproduzcan desde diferentes espacios mediáticos de la región. Cabe destacar también su pertenencia a la empresa Painé S.A., propiedad de la familia Rodríguez Saá, la más representativa históricamente en el poder estatal de la provincia. Todas estas características dan cuenta de la centralidad que ocupa este medio al momento de difundir información a otros sectores de la provincia e incluso superando sus fronteras.

El corpus analizado incluye todas las publicaciones que involucran temas relacionados con la comunidad rankülche de San Luis y que se distinguen para este estudio en tres diferentes momentos. Uno de ellos está relacionado con la restitución de tierras (enjunio y agosto de 2007) como primer hecho que concreta una reivindicación indígena en la región. Un segundo momento se vincula con la inauguración de las viviendas y el inicio de la vida en el lugar para los pobladores rankülche, en mayo de 2009. Finalmente un tercer momento contiene publicaciones relativas al desarrollo de actividades dentro del pueblo, una vez trascurridos algunos años desde su fundación. Se trata de seis notas que se concentran sobre el primer hecho, seis que divulgan el segundo acontecimiento y ocho noticias (con diversas fechas) que se incluyen en el tercer momento y que aparecen de modo disperso, con información variada, de acuerdo con la necesidad e interés del medio de publicar contenidos referidos a los rankülches. Además, se presentan las tres publicidades que aparecen en el espacio publicitario del diario -en medio de las notas analizadas- y que aluden a los actos de reivindicación.

Cabe destacar también que se recuperaron notas de medios gráficos nacionales (dos de La Nación, una de La Prensa y una de Página 12), aquellas que emitieron información sobre el acontecimiento de creación de Pueblo Ranquel de San Luis y a partir de las cuales es posible identificar la manera diversa en que el tema es presentado a nivel nacional. Finalmente el trabajo se complementa con los resultados de una investigación reciente en "Pueblo Ranquel" (Giacomasso, 2016)que permiten relacionar y contextualizar el caso de análisis³

3 El trabajo etnográfico en la comunidad se realizó entre los años 2013 y 2015. A partir de la permanencia en el lugar y el diálogo con sus pobladores pudieron relevarse las características principales del pueblo, desde su historia, infraestructura, gobierno y forma de administración; hasta las relaciones sociales, los modos de vida de sus habitantes y las actividades que desempeñan. Es desde ese marco de referencia que también fue posible indagar acerca del tipo de tratamiento mediático realizado frente a la diversidad de acontecimientos y prácticas vinculadas a los rankülches. 


\section{Desarrollo}

\subsection{Los indígenas rankülches como noticia. Temas y voces involucradas}

En un primer nivel de análisis fue necesario especificar el modo en que el pueblo rankülche de San Luis se convierte en noticia para El Diario de la República, cabecera provincial. En las notas relevadas se observó que su visibilización mediática se produce fundamentalmente cuando existe un hecho concreto de "reparación" o "reivindicación" efectivizado por el gobierno de la provincia y protagonizado más específicamente en la figura del gobernador Rodríguez Saá. Esta cuestión puede leerse ligada a la adscripción rankülche que posee el gobernante y que le otorga doble legitimidad ante los hechos relacionados al pueblo, tanto sea por su cargo de autoridad principal como por su propia ascendencia rankül (Giacomasso, 2016). En este punto, queda claro también que el cubrimiento realizado por el medio está marcado por la pertenencia del gobernador a la familia propietaria del diario.

Por otra parte, además de identificar cuándo este medio habla de lo indígena, es interesante analizar cómo refiere al tema y qué voces utiliza para construir las noticias. En las diferentes notas se observa que los discursos que predominan son institucionales, es decir, provienen de funcionarios que integran el gobierno o profesionales técnicos que tienen alguna relación con este. La palabra rankülche se advierte, sin embargo, en ínfimas oportunidades y es representada por el lonko (jefe o cacique) de la comunidad, quien asume la figura de administrador de la coparticipación del Estado y es el referente principal en la coordinación de acciones entre el gobierno y el municipio (Giacomasso, 2016).

Varios ejemplos son muestra de ello. En el primer momento de publicaciones sobre la restitución de tierras existe un uso recurrente de la voz del gobernador, mediante el recurso de "Atribución", así denominado por las Teorías de la Valoración (Martín \& White, 2005; Kaplan, 2004), el cual supone introducir la palabra del otro explícitamente a fin de alinearse, en este caso, con la postura del hablante. Algunas frases utilizadas son: "Ranqueles, la provincia de San Luis quiere reconocerles el derecho a la dignidad ${ }^{4}$, para ello contribuirá con los medios económicos para reparar tantas injusticias"; "vamos a iniciar aquí las obras y vamos a apoyar un proyecto económico sustentable que le dé a pueblo ranquel suficiente autonomía (...) quiero decirles que hoy toda la provincia me acompaña (El Diario de la República, 2007, agosto 15, p. 2-3).

Otros discursos recuperados son, por un lado, los de la Ministra de Inclusión y Desarrollo Humano que refiere puntualmente a la activación producida desde el Estado en torno a la reivindicación indígena como "un proyecto para todas las comunidades y un gran esfuerzo para que se pueda extender a todo el país”. Y por otro lado, también se retoma la palabra del Jefe del Subprograma Parque de las Naciones quien además fue el responsable del

4 De ahora en adelante se entenderá el resaltado en cursiva como propio de la autora de este artículo. 
diseño arquitectónico del pueblo. En cuanto al diseño cabe destacar la particularidad de las obras que reproducen formas análogas a las antiguas tolderías (rukas) rankülches recreando un paisaje similar a los grupos del pasado, por ello es interesante destacar cómo esta peculiaridad es difundida por el medio. En este caso es la voz del arquitecto la que explica que "el gobernador propuso la construcción tipo toldos, pero con materiales modernos" y que "los bocetos y maquetas presentadas fueron producto de una investigación sobre costumbres del pueblo que fue reforzada con el intercambio y consenso de la comunidad" (El Diario de la República, 2007, noviembre 28, p. 10). No obstante, si bien en los artículos hay una continua referencia a la construcción de las viviendas "según criterios y costumbres tradicionales ranqueles" y "contemplando formas de los antepasados", no se registra la voz de los representantes rankülches como testimonio que dé cuenta de estos aspectos culturales e identitarios reflejados en la materialidad del lugar. A su vez, cuando la nota refiere a la bendición indígena que se hace de la tierra tampoco se recuperan los discursos de sus protagonistas. El periodista escribe: "los ranqueles tuvieron la intención de tomar la palabra (...) intentaron explicar a Rodríguez Saá su gratitud, pero su música hizo el trabajo (...) buscaron explicarle la significación de este día, pero las palabras no fueron necesarias, diferentes loncos comenzaron a tocar las trutrucas logrando un sonido que describía el paisaje" (El Diario de la República, 2007, agosto 15, p. 32). En este caso, al limitarse la palabra de los propios actores -lo que en la teoría de la valoración se llama "contracción dialógica” (White, 2003) - se trata de una mera interpretación periodística que restringe la multiplicidad de sentidos que los rankülches pudieran otorgarle a la música y sus prácticas.

Del mismo modo ocurre en un segundo momento de publicaciones relativas a la inauguración del Pueblo Ranquel en el año 2009 (Figura 1). Si bien las notas remiten a las prácticas que los habitantes comenzarían a implementar, tales como el desarrollo de un sistema económico de producción, la implementación en la escuela de una "educación que respete la historia y las creencias de la comunidad" y en el hospital la etnomedicina por su "conexión con la cultura" (El Diario de la República, 2009, mayo 28, p. 8-9), lo cierto es que la noticia se amplía con las explicaciones del gobernador y/u otros profesionales. De esta manera el proyecto se presenta independiente de los reclamos, deseos y/o necesidades de la comunidad, como tratándose de un listado de tareas propuestas que los habitantes tuvieran que efectivizar.

Esto parece más claro en la palabra recuperada del Jefe del Programa de Preservación del Patrimonio Histórico Cultural de San Luis: "Cuando todo haya concluido [en referencia al acto de inauguración], inmediatamente cada uno deberá comenzar a desempeñar el rol correspondiente en la comunidad para su funcionamiento y sustentabilidad" (El Diario de la República, 2009, mayo 29, p. 14). Detrás de estas citas también se aprecia una representación del indígena como receptivo, sobre la que se volverá más adelante. 
Figura 1. Notas de tapa que difunden la inauguración del pueblo. Fotografías propias.

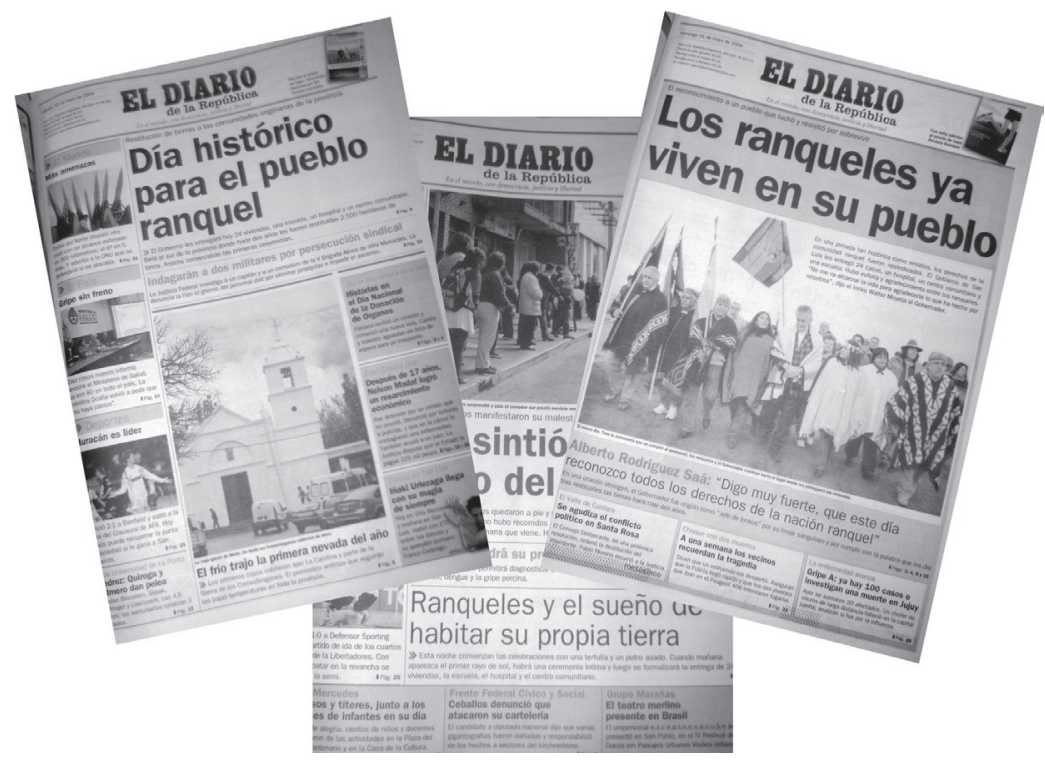

Por otro lado, cuando la noticia se matiza con el discurso de algún representante indígena, más que para recuperar sus perspectivas sobre los hechos, su cultura y proyección de vida, se realiza a los fines de valorar la acción y gestión gubernativa. El periodista cuenta como el representante de la comunidad Coya de Jujuy "sostuvo que es necesario que los demás gobiernos se contagien de San Luis" (El Diario de La República, 2007, noviembre 28, p. 14) y también en otras citas aparece la voz de un representante rankülche afirmando: “A mí me va a ser poca la vida para terminar de agradecerle a Rodríguez Saá lo que ha hecho por nosotros" (El Diario de la República, 2009, mayo 31, p. 4).

Por último, el tercer momento al que nos referimos para este análisis, relacionado con publicaciones sobre "Pueblo Ranquel" efectuadas en años posteriores a la inauguración de las viviendas, podría cobrar otros sentidos en torno a divulgar acciones que tomen como actores centrales a los indígenas. Sin embargo, se observa que si bien los temas aluden a las actividades llevadas a cabo en el pueblo (trátese de visitas a la escuela, festejos del año nuevo rankül, adiestramiento de caballos, crecimiento de la hacienda, etc.) las voces que se reproducen siguen siendo la de funcionarios. Así, por ejemplo, "la Jefa del Programa Culturas Originarias agregó que los ranqueles participaron de charlas debate (...) explicó que festejan la llegada del año nuevo entre el 20 y 24 de junio" (El Diario de la República, 2015, noviembre 2, p. 2); "la ministra de turismo destacó que la idea es que ellos [los ranqueles] se sientan acompañados" (El Diario de la República, 2015, junio 22, p. 5); el "asesor productivo y 
veterinario comentó que la relación caballo-indio es la que buscamos recuperar" (El Diario de la República, 2014, septiembre 21, p. 3) y "el entrenador de caballos recuerda que el ranquel y sus caballos eran un mismo ser (...)" (El Diario de la República, 2014, diciembre 22, p. 3). En estas producciones periodísticas se legitiman las voces de "profesionales", "asesores", "ministros", como enunciados autorizados, mientras que la palabra de los representantes indígenas tiene un lugar restringido o nulo en el discurso del medio. Esto muestra la actitud del hablante de limitar la posibilidad de expresión de estos actores que son hablados por "otros". El único poblador rankülche mencionado y citado es el lonko de la comunidad cuya voz se recupera sólo en una ocasión, para referir al proyecto de contacto de los jóvenes con otras escuelas, dando cuenta de la precariedad del espacio que le es otorgado en comparación con el resto de las voces. Esta cuestión puede ser entendida, en términos de Bourdieu (1997) como formas diferenciales y desiguales de acumulación y concentración del "capital simbólico" (poder reconocido), en este caso entre los agentes institucionales y los grupos indígenas. Según la conceptualización del autor, el Estado funciona como el principal agente de legitimación, lo cual radica en el poder simbólico que ostenta por disponer de los medios eficaces para imponer las categorías de percepción y apreciación. En ese sentido, aquellos poseedores de una función, cargo o titulación otorgada por el Estado se vuelven personajes autorizados, lo cual tiene efectos excluyentes sobre otras poblaciones a quienes se las priva de reconocimiento y consideración (Bourdieu, 1997). Tal como se mencionó anteriormente, los grupos indígenas de América Latina, desde los procesos de colonización, ocuparon una posición marginal, a partir de estructuras de dominación que no fueron sólo materiales, sino también simbólicas, basadas en la invisibilización, silenciamiento e inhabilitación de estos pueblos de decir su propia palabra (Bonfil Batalla, 1972). Si bien en un contexto de reemergencias y de reconocimiento de los derechos indígenas comienzan a surgir trabajos que reivindican sus propias voces y modos de auto-representación, en las noticias relevadas se pone en evidencia que aún queda mucho camino por recorrer para reconocer e integrar el punto de vista o subjetividad de los "otros" (no europeos) $)^{5}$.

Por último, en cuanto a este tercer momento de análisis cabe destacar, además, que las notas referidas al desarrollo del pueblo son pocas y dispersas, lo cual demuestra un decaimiento en el interés del diario por hacer noticia "lo rankülche" si se lo compara con las etapas previas de restitución e inauguración -centradas en la acción del Estado- donde las noticias fueron más frecuentes.

5 Respecto de esta cuestión, y desde una perspectiva decolonial, existen numerosos trabajos que discuten acerca de la necesidad de recuperar los "saberes otros", aquellos que fueron considerados "atrasados", "bárbaros", "primitivos" o "subdesarrollados", negados estratégicamente por el poder hegemónico occidental. La ruptura con la colonialidad del saber es lo que permitirá la construcción del conocimiento localizado, a partir de otras formas de subjetividad, de cultura y de producción y circulación del saber (Mignolo, 2010; Quijano, 2007; Walsh, 2008; entre otros). 
ETNICIDAD, POLÍTICA Y MEDIOS DE COMUNICACIÓN...

\subsection{Las representaciones sobre lo indígena y su relación con el Estado}

En un segundo nivel de análisis interesó identificar la forma en que los indígenas aparecen representados en la prensa, así como también el modo en que se los visualiza según sus relaciones con el Estado. Para ello, se tuvo en cuenta una categoría válida de análisis que es la de subjetivema, desarrollada por KerbratOrecchioni, quien parte de la base de que "toda unidad léxica es, en un cierto sentido, subjetiva, dado que las 'palabras' de la lengua no son jamás otra cosa que símbolos sustitutivos e interpretativos de las 'cosas'" (Kerbrat-Orecchioni, 1997, p. 91-92). En ese sentido, los subjetivemas son frases o palabras que manifiestan la valoración que el hablante hace durante su enunciación de ciertos objetos o hechos del mundo que refiere (Balmayor, 2001, p. 133). En las notas de El Diario de la República estos elementos se rastrearon para dar cuenta de las valoraciones que se construyen en torno a los indígenas y su relación con las políticas de Estado.

En principio se destaca que los rankülches son denominados mayormente como pueblo o comunidad originaria del actual territorio argentino. El sentido de originario no sólo se ve reflejado en el término que los nombra, sino en el modo en cómo se articula el texto de la noticia. Así, frases como "dieron el primer paso en la era del regreso", "la comunidad se reencontró con las tierras de sus antepasados", "las tierras les fueron devueltas", "el paisaje, ese que siempre fue de ellos", son ejemplos de esta idea de pertenencia originaria de los rankülche a estas tierras.

Por otra parte, el concepto de "restituir", también de uso frecuente, alude a otro significado: el que supone la existencia de algo propio que, para poder ser restituido, tuvo previamente que haber sido quitado. No obstante, la mención en las notas a los "atropellos" e "injusticias" cometidas hacia los indígenas se realiza a fin de resaltar la acción de gobierno reparadora ante aquello, sin profundizar en cuestiones históricas, sociales y políticas que pudieran contextualizar los actuales hechos reivindicatorios.

En este sentido, una nota titulada "Una restitución necesaria” (El Diario de la República, 2007, noviembre 18) nombra a los pueblos indígenas como "sector vulnerable" de la sociedad argentina, "despojado", "discriminado" y "estigmatizado en los males más variados". A partir de esta representación se enfatiza en la gestión del gobierno consecuente que, además, es valorada subjetivamente por el periodista, a través de algunas frases o subjetivemas que muestran un claro posicionamiento ante el tema: "Reunir una comunidad aborigen y celebrar su ubicación en un espacio de San Luis es un acto de justicia y profunda sensibilidad"; "surge de la grandeza del saludable gesto de restitución", supone una "buena forma de darse un baño de humildad y reconocer las tradiciones, la cultura, los antepasados".

En relación con lo anterior, otra representación que subyace en las notas es la de una posición indígena receptiva frente a los actos encabezados por el primer mandatario y sus funcionarios. Ello se visualiza principalmente en las 
noticias que detallan los bienes otorgados a la comunidad, donde se especifica que "los ranqueles recibieron yeguas (...) cabezas de ganado" y "se les dio información técnica del programa ProHuerta del INTA quien les brindó semillas para obtener diversas hortalizas". Esta cuestión se ve reforzada por las palabras citadas de un representante indígena quien solicita que "los gobernadores de otras provincias tomen este ejemplo porque en cada comunidad hay un aborigen esperando algo" (El Diario de la República, 2009, mayo 3, p. 4). El indígena es representado desde un lugar pasivo, mientras que la activación y movilidad parece reservada para el gobierno provincial. Sumado a ello, ninguna noticia incluye información y/o testimonios que remitan a luchas, movilizaciones o gestiones concretas que los rankülches hubieran realizado previo a los actos de restitución mencionados. Sólo en una oportunidad y de manera muy efímera se emplea el concepto de "reclamos", aunque nuevamente con el fin de poner el énfasis en la acción gubernamental que se ocupó de atender a los mismos, a diferencia de otras políticas de Estado. "En otras provincias argentinas existen diferentes movimientos que realizan este reclamo [como si se tratara, además, de un reclamo común y universal de todas las comunidades] y siguen siendo desoídos". Aun remitiendo a las demandas de estos pueblos la construcción del texto sigue situando la actividad desde el Estado provincial, presentando la cuestión indígena dentro del marco de la acción pública y no como organización propia.

En estas construcciones mediáticas, la relación entre el Estado y los indígenas puede pensarse bajo la noción de "poder tutelar" (Souza Lima, 1995) basada en la necesidad de estos pueblos de ser protegidos y resguardados. La representación de los indígenas asociada a la vulnerabilidad contribuye a resaltar el papel del Estado como tutor y protector, cuya acción es fundamental para sostenerlos y ampararlos. Pese a que esta concepción ya ha sido superada a nivel nacional e internacional a través del Convenio 169 de la OIT y de la Declaración de las Naciones Unidas donde se reconoce el derecho de los pueblos a determinar libremente sus formas de vida, estos sentidos no aparecen reflejados en el contenido de las notas. Ello implicaría representar la igual capacidad de los indígenas para tomar decisiones y llevar a cabo sus propios proyectos y, en ese sentido, entraría en contradicción con la representación que los muestra vinculados sólo a programas del Estado o como "sector vulnerable". Asimismo, las políticas de tutelaje parecen también reflejarse en un párrafo de estas notas que anuncia que "el mes próximo será el turno de los huarpes [otro pueblo considerado originario de la región], cuando el gobierno provincial les restituya las tierras", como si se tratase de metas aisladas, desti-

6 Este concepto ha sido utilizado por el antropólogo brasileño Souza Lima para analizar críticamente la histórica actuación del Estado brasileño frente a los indígenas. Plantea la posición de protección fraternal y tutela que asume el Estado confiriéndole al "indio" en el Código Civil Brasileño el status jurídico de "incapacidad civil relativa" (art. 6). 
nadas a un grupo que recibirá en un determinado momento aquello dispuesto por el Estado.

Por otra parte, en torno a temas vinculados con la historia y la cultura de los rankülches una noticia que se diferencia del resto es aquella que incluye en su contenido la histórica masacre a los rankülches en los campos de Pozo del Cuadril en 1878, en la cual se recuperan las características del grupo y su vinculación con la actual provincia de San Luis. Esta pareciera ser la excepción de un conjunto de publicaciones en donde el foco está puesto en las gestiones de gobierno y no tanto en la cuestión de la historia y el derecho indígena. Asimismo, cabe destacar que en este particular artículo se hace énfasis en que tal ataque "quedó en el olvido", o fue "pocas veces iluminado por la historia oficial", dando cuenta de la importancia de rescatar estas otras versiones del pasado desde la propia palabra silenciada de los descendientes. No obstante, resulta paradójica la defensa de "la voz acallada de los pueblos originarios", cuando las noticias producidas por el medio han incluido escasamente la palabra de representantes indígenas y, por el contrario, han centrado el discurso en la voz de los funcionarios gubernamentales.

Esto último puede explicarse también, siguiendo a Tuchman (1983) desde una perspectiva sociológica de producción de mensajes, a partir de la existencia de ciertos presupuestos periodísticos basados en que la credibilidad de la noticia se logra si la fuente de información la constituyen los sujetos situados en los lugares más altos de las jerarquías organizativas. Desde dicha postura, los periodistas dan primacía a aquella información otorgada por los departamentos de los organismos públicos, la cual estaría garantizada por la supuesta rectitud de las instituciones ya legitimadas. En este sentido, es que el autor refiere a la noticia como un procedimiento ideológico, en tanto "construye la realidad" o la enmarca, seleccionando de antemano unos elementos por sobre otros.

\subsection{Reivindicación indígena y propaganda política}

Otro punto a destacar de las publicaciones vinculadas a los rankülches es aquel que auspicia explícitamente el gobierno de la provincia a través de información propagandística relacionada con los actos de "reparación cultural" (Figura 2). Estas secciones nuevamente impiden pensar lo relativo al pueblo rankülche por fuera de la acción del Estado que es la que lo viabiliza y direcciona.

Se trata de mensajes firmados por el gobierno que muestran a los lectores el compromiso político asumido con esta comunidad. Se valora "la dignidad" de las acciones, el "mayor acto de inclusión social" y la "idea y tesón" del Estado "para darle a esa gente lo que le pertenece". El discurso se vincula con la acción y los méritos de los gobernantes. 
Figura 2. Propaganda política sobre los actos de reivindicación hacia los rankülches. Fotografías propias.

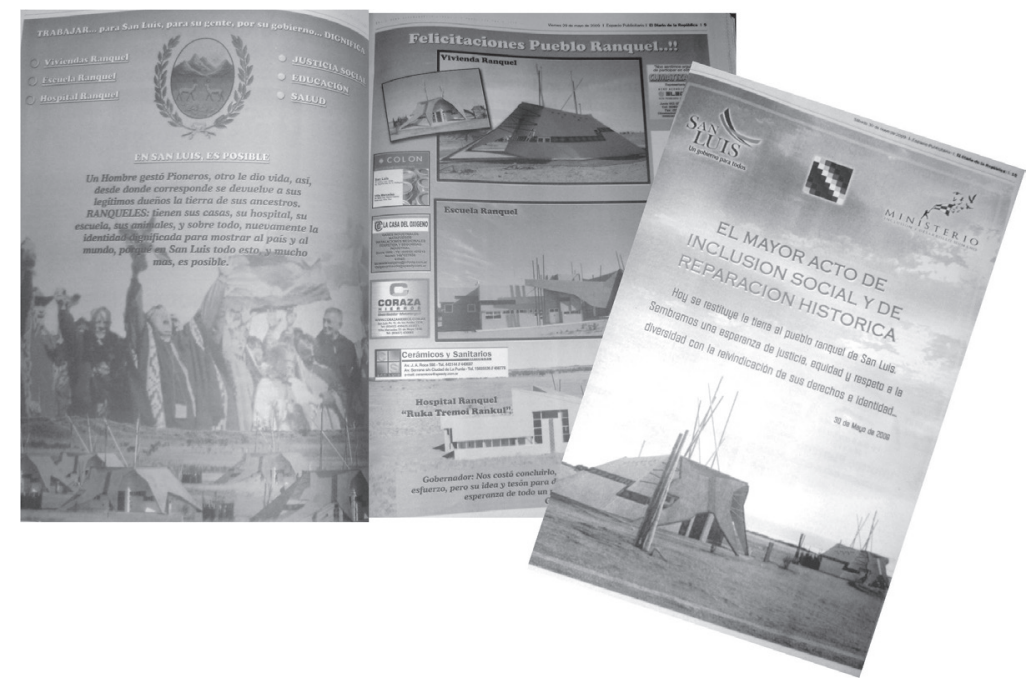

Por otra parte, la propaganda estatal fue utilizada además para invitar al público a la ceremonia de restitución de tierras y de entrega de las viviendas (Figura 3). En estos casos vale advertir sobre la imagen utilizada de Pincen -un reconocido cacique rankül- para representar a los indígenas rankülches que "triunfantes...VUELVEN", reafirmando en ese texto la idea de recuperar su territorio original. La fotografía seleccionada con el torso desnudo, el chiripá, la vincha, las boleadoras y la lanza, reproduce una visión estereotipada del indígena que, a su vez, se refuerza con la representación que lo asocia con la ruralidad. Es posible pensar que tal elección se relaciona con la intención de exhibir y difundir una imagen que fuese fácilmente identificada por la sociedad con "lo indio", a partir de la presencia de elementos específicos a este asociados.

De tal modo, a través de estas publicaciones se propaga una construcción tipificadora de lo indígena, fundada en un esquema de cualidades que difieren de las características visibles actuales de los rankülches. Desde esta representación, la identidad de estos pueblos es "esencializada" o "romantizada", vinculada con un modo de vida "atrasado", alejado en tiempo y espacio; lo cual aseguraría la condición de "pureza" cultural, legitimada desde la lógica y el imaginario social dominante (Benavides, 2005). Esto demuestra los "efectos de autenticidad" (Lazzari, 2007b) y los modos hegemónicos de visibilización que aún se reproducen en torno a los sujetos e identidades indígenas. 
Figura 3. Invitación pública a la ceremonia de restitución de tierras. Fotografía propia.

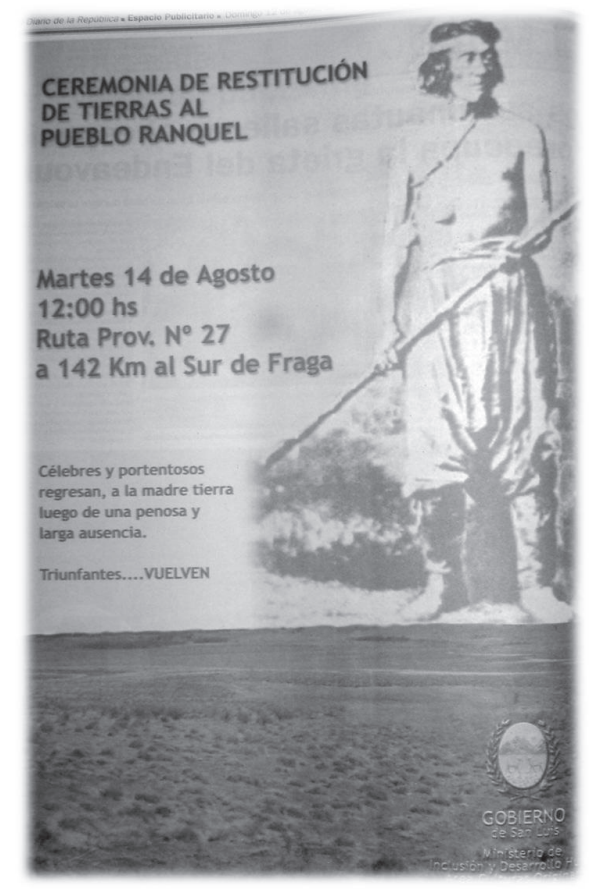

Cabe preguntarse, aunque tal análisis exceda este trabajo, ¿qué relaciones y expectativas acerca de lo "indio" se promueven y/o reafirman en los pobladores locales a través de las imágenes estereotipadas difundidas?

\subsection{Los rankülches en otros medios de prensa}

Es interesante destacar, además, la forma en que reconocidos medios de prensa nacionales han difundido información acerca de los indígenas rankülches de San Luis. Las notas relevadas divulgan, por un lado, los hechos de restitución y fundación del Municipio Ranquel como una "iniciativa histórica" de la provincia y como un "precedente" en la reparación de las culturas originarias en nuestro país (Diario La Nación ${ }^{7}$ y La Prensa ${ }^{8}$ ). Estas son mayoritariamente descriptivas de las características del pueblo y de los emprendimientos productivos de sus pobladores, sin ahondar en aspectos políticos, históricos y/o culturales indígenas. Por otro lado, otras notas emitidas por La Nación ${ }^{9}$ y Página $12^{10}$ presentan una postura más crítica y hacen hincapié en el gasto público que significó la

\footnotetext{
7 Nota del 16 de agosto de 2009. Fundan el Municipio Ranquel en San Luis.

8 Nota del 7 de junio de 2009. Los ranqueles tienen su Nación.

9 Nota del 11 de julio de 2010. Las increíbles "Siete maravillas" de Rodríguez Saá.

10 Nota del 23 de mayo de 2010. La tierra de la pirámide y el Cabildo.
} 
construcción del Municipio Ranquel, por tratarse de "otra obra monumental que buscó atraer al turista a cualquier precio". Asimismo, en ambas publicaciones se cuestiona al gobernador Rodríguez Saá por "la desmesura de una alta inversión" para edificar en una de las lagunas del pueblo un anfiteatro flotante, enfatizando la discusión en base a la inadecuada gestión del Estado provincial.

De manera general se aprecia que las notas nacionales, al igual que las publicaciones del diario provincial, vinculan a lo rankülche con las políticas oficiales que, aunque sean juzgadas positiva o negativamente, son las que terminan por visibilizar y dar cuenta mediáticamente de la existencia de este pueblo indígena.

\section{Conclusiones}

En este artículo, si bien el objetivo principal fue analizar las formas en que se visualizan y representan los indígenas rankülches de San Luis en la prensa gráfica, la intención final es que este particular estudio sirva para análisis comparados sobre la temática. En este sentido, se arguyen algunas conclusiones que se desprenden del desarrollo y que aportan al debate sobre el lugar social que parecen ocupar los pueblos indígenas en un contexto actual de reemergencias.

Tal como se explicitó en un apartado anterior, se han producido importantes avances en materia de reconocimiento de los derechos indígenas, basados en "preservar, desarrollar y transmitir a las generaciones futuras sus territorios ancestrales y su identidad étnica (...) de acuerdo con sus propios patrones culturales, instituciones sociales y sistemas legales" (Martínez Cobo, 1986, p. 87). En este contexto la participación de los pueblos indígenas en diferentes ámbitos como los medios de comunicación, se vuelve también una cuestión de derechos que interpela a los medios a propiciar y crear espacios de opinión pública que reconozcan la pluralidad, la interculturalidad y asuman como responsabilidad social la eliminación de los estereotipos y las estigmatizaciones con que se construye la información.

En este trabajo se observó, en primer lugar, que las noticias analizadas son presentadas a través de la voz de funcionarios, desestimando las voces de los propios actores indígenas. Es decir, no hay una revalorización de sus discursos para explicar los temas que los involucran. Frente a esta cuestión algunos autores plantean la importancia de que los medios amplíen los lugares de discusión y la inclusión de diferentes voces para que la información sea tratada con su debida contextualización y con un lenguaje inclusivo de la pluralidad de perspectivas (Cytrynblum, 2009). En las notas relevadas, la articulación de los mismos referentes discursivos, vuelven los hechos lineales, sin manifestaciones de conflicto, confrontación, resistencias y/o negociaciones y, por ende, todo transcurre en un clima armónico y de consenso. Se trata de miradas parciales que 
recortan la gran pintura que rodea a temas tan complejos como los vinculados con los procesos de reivindicación, lucha y reconocimiento de derechos.

En segundo lugar, se destacó la reproducción de estereotipos que asocian lo indígena con una actitud paternalista del Estado o como no autosuficientes y, en otros casos, también desde una visión romantizada de "lo indio" (bien clara en la imagen publicitaria), ligada a formas tradicionales de vida de estos grupos.

En suma, el análisis de los textos periodísticos reviste una particularidad interesante, puesto que los mismos trasmiten representaciones sociales que no tienden a manifestarse como tales -como en el caso de la publicidad o los productos de la industria cultural y el entretenimiento (la literatura, el cine, la música) - sino bajo la forma de "datos" de la "realidad". Esta no es una cuestión menor si se entiende a los medios -y aquí se incluye al discurso periodístico- como recursos de poder simbólico (Thompson, 2007) que construyen la información (re)produciendo representaciones e identidades sociales hegemónicas. Por tal razón una mirada crítica al respecto puede contribuir a desentrañar estos aparentes "hechos directos" y reflexionar sobre las estrategias de legitimación mediática de ciertos saberes e imágenes. En el caso de los pueblos indígenas, como actores históricamente silenciados, una postura de este tipo vuelve posible exigir formas de inclusión y de visibilización alternativas que contrarresten versiones "autorizadas" y complejicen los temas abordados desde la diversidad de posicionamientos.

\section{Referencias bibliográficas}

Abric, J. (1994). Practiques sociales et Représentations. México: Ediciones Coyoacán.

Balazote, A. \& Radovich, J (1992). La problemática Indígena. Estudios antropológicos sobre poblaciones indígenas de la Argentina. Buenos Aires: CEAL.

Balmayor, E. (2001). La enunciación del discurso. En R. Marafioti (Ed.), Recorridos semiológicos (pp.111-178). Buenos Aires: Eudeba.

Benavides, H. (2005). Los ritos de la autenticidad: indígenas, pasado y el Estado ecuatoriano. Arqueología Suramericana 1, 5-25.

Bonfil Batalla, G. (1972). El concepto de indio en América: una categoría de la situación colonial. Anales de Antropología IX, 105-124.

Bonfil Batalla, G. (2004). Pensar nuestra cultura. Nuestro patrimonio cultural: un laberinto de significados. Diálogos en la acción 1, 117-134.

Bourdieu, P. (1997). Méditations pascaliennes. París: Seuil.

Briones, C. (1998). La Alteridad del Cuarto Mundo. Una Deconstrucción Antropológica de la Diferencia. Buenos Aires: Ediciones del Sol.

Caletti, S. (2006). Comunicación y espacio público. Notas para repensar la democracia en la sociedad contemporánea. Buenos Aires: Mimeo. 
Canuhé, G. (2010). Los rankülche: sobre la huella de Mansilla. San Luis: Gobierno de San Luis.

Carrasco, M. (2002). El movimiento indígena anterior a la reforma constitucional y su organización en el Programa de Participación de Pueblos Indígenas. Recuperado de http://bit.ly/2v4wNeg.

Carrasco, M. \& Briones, C. (1996). La tierra que nos quitaron. Reclamos indígenas en Argentina. Copenhague: Serie Documentos en Español \# 18. IWGIA.

Cebrelli, A. \& Rodríguez, M. G. (2013). Algunas reflexiones sobre representaciones y medios. Revista Tram[p]as de la Comunicación y la Cultura 76, 89-99.

Cytrynblum, A. (2009). Periodismo social. Una nueva Disciplina. La Crujia: Buenos Aires.

Fairclough, N. \& Wodak, R. (1997). Critical Discourse Analysis. In van Dijk, T.A. (ed.), Introduction to Discourse Analysis (pp. 258-284). London: Sage.

Frites, E. (2011). El derecho de los pueblos indígenas. Buenos Aires: Programa Naciones Unidas para el Desarrollo- PNUD.

Giacomasso, M. V. (2016). Patrimonio, discursividades y políticas culturales indígenas: un análisis en Pueblo Ranquel, San Luis, Argentina (Tesis Doctoral). Disponible en http://bit.ly/2wthAkw.

Gómez, M. (1997). Derecho indígena. Instituto Nacional Indigenista. México City: Asociación Mexicana para las Naciones Unidas.

Jodelet, D. (1993). La representación social: fenómenos, conceptos y teoría. En G. Moscovici, (Ed.), Psicología Social II, (pp. 469-494). Barcelona: Paidós.

Kaplan, N. (2004). Nuevos desarrollos en el estudio de la evaluación en el lenguaje: la Teoría de la Valoración. Boletín de Lingüística 22, 52-78.

Kerbrat-Orecchioni, C. (1997). La enunciación. De la subjetividad en el lenguaje. Buenos Aires: Edicial.

Lazzari, A. (2007). Historias y reemergencias de los pueblos indígenas. En Funes \& A. Lazzari (Eds.), Explora. Las ciencias en el mundo contemporáneo, (pp. 1-16). Buenos Aires: Ministerio de Educación, Ciencia y Tecnología de la Nación.

Marcová, I. (1996). En busca de las dimensiones epistemológicas de las representaciones sociales. En D. Páez \& A. Blanco (Eds.). La teoría sociocultural y la psicología social actual. Madrid: Fundación Infancia y Aprendizaje SL.

Martin, J. \& White, P. (2005). The language of evaluation. Appraisal in English. Palgrave: Londres.

Martínez Cobo, J. R. (1986). Estudio del problema de la discriminación contra las poblaciones indígenas. Conclusiones, propuestas y recomendaciones. New York: ONU.

McCombs, M. (2004). Setting the Agenda. The Mass Media and Public Opinion. Cambridge: Paidós.

Mignolo, W. (2010). Desobediencia epistémica: retórica de la modernidad, lógica de la colonialidad y gramática de la descolonialidad. Buenos Aires: Ediciones del Signo.

Moscovici, S. (1993). Psicología Social II. Buenos Aires: Paidós. 
Navarro Florida, P. (1999). Un país sin indios. La imagen de La Pampa y la Patagonia en la geografía del naciente estado argentino. Scripta Nova. Revista electrónica de Geografía y Ciencias Sociales 51. Recuperado de http://www.ub.edu/ geocrit/sn-51.htm.

Quijano, A. (2007). Colonialidad del poder y clasificación social. En R. Grosfoguel \& S. Castro-Gómez (Eds.), El giro decolonial. Reflexiones para una diversidad epistémica más allá del capitalismo global, (pp. 93-126). Bogotá: Iesco / Instituto Pensar / Siglo del Hombre.

Slavsky, L. (1992). Los indígenas y la sociedad nacional. Apuntes sobre política indigenista en Argentina. En C Radovich \& A. Balazote (Eds.), La problemática indígena. Estudios antropológicos sobre pueblos indígenas de Argentina, (pp.6779). Buenos Aires: Centro Editor de América.

Souza Lima, A. (2010). Poder tutelar y formación del estado en Brasil: Notas a partir de la Creación del Servicio de Protección a los Indios y localización de Trabajadores Nacionales. Desacatos 39, 53-66.

Tamagno, L. (2002). La historia del genocidio o una historia de genocidios. Trabajo presentado en el Coloquio Historia y Memoria. La Plata: Facultad de Humanidades y Ciencias de la Educación UNLP.

Thompson, J. (1997). Los media y la modernidad. Una teoría de los medios de comunicación. Barcelona: Paidós.

Tuchman, G. (1983). La producción de la noticia. Estudio sobre la construcción social de la realidad. Barcelona: Gustavo Gili.

Verón, E. (2001). Interfaces: sobre la democracia audiovisual avanzada. En E. Verón (Ed.), El cuerpo de las imágenes. Buenos Aires: Norma.

Walsh, C. (2008), Interculturalidad crítica / pedagogía decolonial. En A.G. Bonilla \& W. Villa (Eds.), Diversidad, interculturalidad y construcción de ciudad, (pp. 44-63). Bogotá: Alcaldía Mayor de Bogotá / Universidad Pedagógica Nacional.

White, P. (2003). Appraisal- The Language of evaluation and stance, en C. Bulcaen (Ed.), The Handbook of Pragmatics, (pp.66-91). Amsterdam/Philadelphia: John Benjamins.

Wodak, R. (ed). (1989). Language, Power and Ideology. Studies in Political Discourse. Amsterdam: John Benjamins. 